\title{
Convergent Inputs from the Hippocampus and Thalamus to the Nucleus Accumbens Regulate Dopamine Neuron Activity
}

\author{
(D)Stephanie M. Perez and $\mathbb{C}^{-D a n i e l}$ J. Lodge \\ Department of Pharmacology and Center for Biomedical Neuroscience, University of Texas Health Science Center, San Antonio, Texas 78229
}

\begin{abstract}
Aberrant hippocampal activity is observed in individuals with schizophrenia and is thought to underlie the augmented dopamine system function associated with psychosis. The pathway by which the ventral hippocampus (vHipp) regulates dopamine neuron activity has been demonstrated previously and involves a glutamatergic projection to the nucleus accumbens (NAc). Recent postmortem studies have confirmed glutamatergic abnormalities in the NAc of individuals with schizophrenia. Specifically, an increase in vesicular glutamate transporter 2 (vGlut2) expression was reported. Although projections from the hippocampus do express vGlut2, inputs from the thalamus are more likely to account for this alteration; however, the role of thalamic inputs to the NAc in the regulation of dopamine neuron activity has not been elucidated. Here, using male Sprague Dawley rats, we demonstrate that a subset of NAc medium spiny neurons receive convergent inputs from the vHipp and paraventricular nucleus of the thalamus (PVT), with both regions working synergistically to regulate dopamine neuron activity. Activation of either the vHipp or PVT increases the number of spontaneously active dopamine neurons in the ventral tegmental area. Moreover, this regulation requires simultaneous activity in both regions because PVT inactivation can reverse vHipp-induced increases in dopamine neuron population activity and vHipp inactivation can reverse PVT-induced increases. This is relevant to schizophrenia because inactivation of either the vHipp or PVT is sufficient to reverse aberrant dopamine system function in two distinct rodent models. These data suggest that thalamic abnormalities may contribute to the aberrant dopamine system function observed in schizophrenia and that the PVT represents a novel site of intervention for psychosis.
\end{abstract}

Key words: electrophysiology; hippocampus; MAM; poly I:C; schizophrenia; thalamus

Significance Statement

Current treatments for schizophrenia are far from adequate and a more complete understanding of the pathophysiology underlying this disease is warranted if we are to discover novel therapeutic targets. We have previously demonstrated that the aberrant dopamine system function observed in individuals with schizophrenia and rodent models is driven by increases in hippocampal activity. We now demonstrate that thalamic (paraventricular nucleus, PVT) and ventral hippocampal afferents converge in the nucleus accumbens to regulate dopamine system function. Such information provides a potential site for therapeutic intervention for schizophrenia. Indeed, inactivation of the PVT can effectively reverse aberrant dopamine system function in two distinct rodent models displaying circuit level alterations and corresponding behavioral deficits relevant to schizophrenia.

\section{Introduction}

Dysregulation of mesolimbic dopamine system function is consistently observed in individuals with schizophrenia and is

\footnotetext{
Received Aug. 18, 2016; revised Sept. 21, 2018; accepted Sept. 22, 2018.

Author contributions:S.M.P. wrote the first draft of the paper; S.M.P. and D.J.L. edited the paper; S.M.P. and D.J.L. designed research; S.M.P. performed research; S.M.P. analyzed data; S.M.P. wrote the paper.

This work was supported by the National Institutes of Health (Grant R01 MH090067 from the National Institute of Mental Health to D.J.L.) and the San Antonio Life Science Institute (SALSI Postdoctoral Scholar Fellowship to S.M.P.). We thank Dr. Angela M. Boley for technical assistance.

The authors declare no competing financial interests.

Correspondence should be addressed to Stephanie M. Perez, Department of Pharmacology and Center for Biomedical Neuroscience, University of Texas Health Science Center, 7703 Floyd Curl Drive, MC 7764, San Antonio, TX 78229. E-mail: Perezsm@uthscsa.edu.

https://doi.org/10.1523/JNEUROSCI.2629-16.2018

Copyright $\odot 2018$ the authors $\quad 0270-6474 / 18 / 3810607-12 \$ 15.00 / 0$
}

thought to contribute to the positive symptoms of the disorder (Laruelle and Abi-Dargham, 1999; Abi-Dargham, 2004). Although the cause of this augmented dopamine system function has not been conclusively demonstrated, it is likely secondary to aberrant regulation by glutamatergic and GABAergic systems (Lewis et al., 1999, 2005; Javitt, 2009; Moghaddam and Javitt, 2012). One such region that has gained increased attention is the hippocampus. Indeed, individuals with schizophrenia display hyperactivity within hippocampal subfields that is correlated with clinical measures of positive symptoms (Heckers, 2001; Schobel et al., 2009). This hippocampal hyperactivity has been modeled in rodents, in which evidence suggests that the dysfunction present in the dopamine system is driven by aberrant hippocampal activity (Lodge and Grace, 2007; Perez and Lodge, 
2013). Specifically, abnormal glutamatergic transmission from the ventral hippocampus (vHipp) leads to an increase in dopamine neuron activity in the ventral tegmental area (VTA) via a polysynaptic circuit involving the nucleus accumbens (NAc) and ventral pallidum (Lodge and Grace, 2011 and see Fig. 8). Consistent with this, recent postmortem studies have revealed glutamatergic abnormalities in the NAc that may contribute to the pathology of the disorder (McCollum and Roberts, 2015).

Vesicular glutamate transporters 1 and 2 (vGlut 1 and vGlut2) are required for the uptake of glutamate into presynaptic vesicles (Bellocchio et al., 2000; Takamori et al., 2000). vGlut1 mRNA is highly expressed in the cortex and hippocampus, whereas vGlut2 is enriched in subcortical structures (i.e., thalamus, amygdala) (Hisano et al., 2000). Interestingly, recent postmortem studies have reported elevated vGlut2 (but not vGlut1) expression in the NAc of individuals with schizophrenia (McCollum and Roberts, 2015). Although the hippocampus does express low levels of this transporter (Fremeau et al., 2001), it is more likely that these reported differences are attributable to altered input from the thalamus because an increase in thalamic vGlut2 expression has been previously reported postmortem in individuals with schizophrenia (Smith et al., 2001). The thalamus is a structure that has been consistently implicated in schizophrenia, with evidence supporting structural abnormalities such as reduced cell number and volume (Clinton and Meador-Woodruff, 2004) and dysfunction in patients (Oke and Adams, 1987; Clinton and Meador-Woodruff, 2004). The thalamus is composed of many nuclei; however, it has been demonstrated that it is the paraventricular nucleus of the thalamus (PVT) that provides the predominant glutamatergic projection to the NAc (Su and Bentivoglio, 1990; Bubser and Deutch, 1998; Pinto et al., 2003; Dong et al., 2017). Moreover, how the PVT regulates mesolimbic dopamine system function has yet to be examined. Here, we investigate the contributions of PVT and hippocampal afferents to the NAc in the regulation of VTA dopamine neuron activity. Furthermore, we provide evidence that the PVT may be a novel site of intervention for the treatment of psychosis by examining its role in under normal conditions and in two distinct rodent models displaying circuit level alterations and corresponding behavioral deficits relevant to schizophrenia: gestational methylazoxymethanol acetate (MAM) administration and maternal inflammation.

\section{Materials and Methods}

Experiments. All experiments were performed in accordance with the guidelines outlined in the National Institutes of Health's Guide for the Care and Use of Laboratory Animals and were approved by the Institutional Animal Care and the Use Committee of University of Texas Health San Antonio.

Animals. Male Sprague Dawley rats were obtained from Envigo and used for the majority of experiments. To generate rodents displaying circuit level alterations and corresponding behavioral deficits relevant to schizophrenia, we used gestational administration of either MAM or polyinosine:cytosine (poly I:C). MAM administration was performed as described previously (Moore et al., 2006; Lodge, 2013). In brief, timed pregnant female Sprague Dawley rats (Envigo) were obtained on gestational day (GD) 16 and MAM (22 mg/kg, i.p.) was administered on GD17. Injections of saline ( $1 \mathrm{ml} / \mathrm{kg}$, i.p.) were administered to control dams. Poly I:C was administered to timed pregnant female Sprague Dawley rats obtained from Envigo on GD11. Poly I:C (7.5 mg/kg, i.p.) or saline ( $1 \mathrm{ml} / \mathrm{kg}$, i.p.) was administered on GD12. Male pups (MAM, poly I:C, and saline controls) were weaned on postnatal day (P) 21 and housed with littermates in groups of $2-3$ until adulthood ( $>$ P60). All experiments were performed on multiple litters of MAM-, poly I:C- and salinetreated rats.
Dopamine neuron electrophysiology. Adult male Sprague Dawley rats (300-450 g) were anesthetized with $8 \%$ chloral hydrate $(400 \mathrm{mg} / \mathrm{kg}$, i.p.) and placed in a stereotaxic apparatus. Chloral hydrate was used for all recordings because it does not significantly depress dopamine neuron activity (Hyland et al., 2002). Supplemental anesthesia was given as required to maintain suppression of limb compression withdrawal reflex. A core body temperature of $37^{\circ} \mathrm{C}$ was sustained using a thermostatically controlled heating pad. Extracellular glass microelectrodes (impedance $\sim 6-10 \mathrm{M} \Omega$ ) were lowered in the VTA (posterior 5.3 to 5.7 ; lateral 0.6 to $1.0 \mathrm{~mm}$ from bregma and -6.5 to- $9.0 \mathrm{~mm}$ ventral of the brain surface) using a hydraulic micro-positioner (Model 640, Kopf Instruments). Spontaneously active dopamine neurons were identified using previously established electrophysiological criteria (Grace and Bunney, 1983; Ungless and Grace, 2012). In short, dopamine neurons were identified with open filter settings (low-frequency cutoff: $30 \mathrm{~Hz}$; high-frequency cutoff: $30 \mathrm{kHz}$ ) and spontaneously active dopamine neurons were recorded while making multiple vertical passes (typically 6-9), separated by $200 \mu \mathrm{m}$ in a predetermined pattern to sample various regions of the VTA. Three parameters of dopamine neuron activity were measured: population activity, defined as the number of dopamine neurons firing spontaneously (Lodge and Grace, 2011), basal firing rate, and proportion of action potentials occurring in bursts.

Intracranial drug administration. For acute, intracranial administration of drugs, a standard guide cannula (26 gauge; Plastics One) with an internal cannula (Plastics One) extending $2 \mathrm{~mm}$ past the end of the guide was used. Tetrodotoxin citrate (TTX; $0.25 \mathrm{ng}$ in $0.75 \mu \mathrm{l})$, NMDA $(0.75$ $\mu \mathrm{g}$ in $0.5 \mu \mathrm{l}$ ), kynurenic acid (KA; $7.5 \mu \mathrm{g}$ in $0.75 \mu \mathrm{l}$ ), or vehicle [Dulbecco's PBS (DPBS); $0.75 \mu \mathrm{l}$ ] was injected immediately adjacent to the PVT (A/P - 2.0; M/L +0.4 mm from bregma; D/V $-5.8 \mathrm{~mm}$ ventral of the brain surface) to avoid damage to the relatively small structure or was injected directly into the vHipp (A/P - 5.3; M/L +5.0 mm from bregma; $\mathrm{D} / \mathrm{V}-6.5 \mathrm{~mm}$ ventral of the brain surface) or NAc $(\mathrm{A} / \mathrm{P}+1.4 ; \mathrm{M} / \mathrm{L}+1.3$ $\mathrm{mm}$ from bregma; $\mathrm{D} / \mathrm{V}-6.6 \mathrm{~mm}$ ventral of the brain surface). Each rat received a combination of unilateral intracranial injections (administered at a rate of $\sim 0.5 \mu \mathrm{l} / \mathrm{min}$ ) depending on the experiment performed and as detailed below. Recordings began $\sim 10$ min after injection and typically lasted for $\sim 2 \mathrm{~h}$ after drug administration, so only a single injection was administered per region, consistent with previous experimental approaches (Floresco et al., 2003; Lodge and Grace, 2007; Aguilar et al., 2014; Zimmerman and Grace, 2016).

Chemogenetic modulation of PVT afferents. All survival procedures were performed under general anesthesia in a semisterile environment. Male Sprague Dawley rats $(220-250 \mathrm{~g})$ were anesthetized with Fluriso ( $2-5 \%$ isoflurane, USP, with oxygen flow at $1 \mathrm{~L} / \mathrm{min}$ ) and placed in a stereotaxic apparatus using blunt atraumatic ear bars. A core body temperature of $37^{\circ} \mathrm{C}$ was maintained. Rats were unilaterally injected $(\sim 0.5 \mu \mathrm{l}$ per min) in the PVT (A/P - 2.0; M/L + $0.4 \mathrm{~mm}$ from bregma; D/V -5.2 $\mathrm{mm}$ ventral of the brain surface) with adeno-associated virus (AAV) expressing the Gq-DREADD receptor vectors driven by the human synuclein promotor (AAV2-hSyn-HA-hM3D(Gq)-mCherry; Addgene: 50474-AAV2; titer- $3.48 \times 10 \mathrm{e} 12 \mathrm{vg} / \mathrm{ml} ; 0.75 \mu \mathrm{l}$ ). Control rats were administered a control viral vector lacking the $\mathrm{hM} 3 \mathrm{D}$ encoding gene (rAAV2/CaMKII $\alpha$-eYFP; UNC Vector Core; $3.8 \times 10 \mathrm{e} 12 \mathrm{vg} / \mathrm{ml})$. Rats were allowed to recover for $6-8$ weeks before testing to allow for robust gene expression in target regions. To activate discrete PVT inputs to the NAc or mPFC, clozapine- $N$-oxide $(\mathrm{CNO} ; 300 \mu \mathrm{M} ; 0.75 \mu \mathrm{l})$ was directly injected into the NAc $(\mathrm{A} / \mathrm{P}+1.4 ; \mathrm{M} / \mathrm{L}+1.3 \mathrm{~mm}$ from bregma; $\mathrm{D} / \mathrm{V}-7.6$ $\mathrm{mm}$ ventral of the brain surface) or $\mathrm{mPFC}(\mathrm{A} / \mathrm{P}+3.0 ; \mathrm{M} / \mathrm{L}+0.6 \mathrm{~mm}$ from bregma; $\mathrm{D} / \mathrm{V}-4.5 \mathrm{~mm}$ ventral of the brain surface) $10 \mathrm{~min}$ before recording. A single injection was administered because the biological effects of $\mathrm{CNO}$ have been reported 6-10 h after administration (Alexander et al., 2009; Guettier et al., 2009). DREADD expression in neurons projecting from the PVT to the NAc or $\mathrm{mPFC}$ were verified histologically using Neurolucida (MBF Bioscience) in combination with a Zeiss epifluorescent microscope.

Chemogenetic modulation of projections to the NAc. Male Sprague Dawley rats $(220-250 \mathrm{~g})$ were anesthetized with Fluriso $(2-5 \%$ isoflurane, USP, with oxygen flow at $1 \mathrm{~L} / \mathrm{min}$ ) and placed in a stereotaxic apparatus using blunt atraumatic ear bars. A core body temperature of $37^{\circ} \mathrm{C}$ was 
maintained. Rats were bilaterally injected $(\sim 0.5 \mu \mathrm{l}$ per $\mathrm{min})$ in the NAc $(\mathrm{A} / \mathrm{P}+1.4 ; \mathrm{M} / \mathrm{L} \pm 1.4 \mathrm{~mm}$ from bregma; $\mathrm{D} / \mathrm{V}-7.6 \mathrm{~mm}$ ventral of the brain surface) with a long-term retrograde herpes simplex virus (HSV) expressing a Cre recombinase driven by the human elongation factor- $1 \alpha$ (hEF1 $\alpha$ ) promotor (HSV-hEF1 $\alpha$-Cre: $0.75 \mu \mathrm{l}$; Massachusetts General Hospital; RN425) or a control virus (hEF1 $\alpha$-EYFP; $0.75 \mu \mathrm{l}$; Massachusetts General Hospital; RN402). At the same time, AAV expressing the Gq-DREADD in a double-floxed inverse open reading frame (AAVhSyn-DIO-hM3D $(\mathrm{Gq})$-mCherry) was injected into the PVT (A/P - 2.0; $\mathrm{M} / \mathrm{L} \pm 0.4 \mathrm{~mm}$ from bregma; $\mathrm{D} / \mathrm{V}-5.4 \mathrm{~mm}$ ventral of the brain surface) or vHipp (A/P $-4.8 ; \mathrm{M} / \mathrm{L} \pm 4.8 \mathrm{~mm}$ from bregma; $\mathrm{D} / \mathrm{V}-7.8 \mathrm{~mm}$ ventral of the brain surface). All rats were allowed to recover for $6-8$ weeks before any testing to allow for robust gene expression in target regions. Twenty minutes before electrophysiology, rats were injected systemically with the DREADD agonist Compound $21(3.0 \mathrm{mg} / \mathrm{kg}$, i.p.; HelloBio; HB6124), used to mitigate potential concerns associated with the back metabolism of $\mathrm{CNO}$ to clozapine following systemic administration (Chen et al., 2015; MacLaren et al., 2016).

Extracellular recordings from putative medium spiny neurons. Adult male Sprague Dawley rats (300-450 g) were anesthetized ( $8 \%$ chloral hydrate; $400 \mathrm{mg} / \mathrm{kg}$, i.p.) and placed in a stereotaxic apparatus. Stimulating electrodes (bipolar concentric; Kopf Instruments) were lowered immediately adjacent to the PVT (A/P $-2.0 ; \mathrm{M} / \mathrm{L}+0.4 \mathrm{~mm}$ from bregma; $\mathrm{D} / \mathrm{V}-5.8 \mathrm{~mm}$ ventral of the brain surface) and within the vHipp (A/P $-5.3 ; \mathrm{M} / \mathrm{L}+5.0 \mathrm{~mm}$ from bregma; $\mathrm{D} / \mathrm{V}-6.5 \mathrm{~mm}$ ventral of the brain surface). Extracellular glass microelectrodes (impedance 6-10 M $\Omega$ ) were lowered into the NAc $(\mathrm{A} / \mathrm{P}+1.4 ; \mathrm{M} / \mathrm{L}+1.3 \mathrm{~mm}$ from bregma and -4.5 to $-7.5 \mathrm{~mm}$ ventral of the brain surface). Putative medium spiny neurons that responded to electrical stimulation $(1 \mathrm{~mA}$; pulse rate: $0.5 \mathrm{~Hz}$; pulse duration: $0.25 \mathrm{~ms}$; delay between PVT and vHipp stimulation: $0.25 \mathrm{~s}$ ) from the PVT, vHipp, or both structures were recorded for 3-5 min and the cells that responded were counted and reported.

Histology. Rats used in chemogenetic studies were transcardially perfused $(150 \mathrm{ml}$ of cold saline immediately followed by $150 \mathrm{ml}$ of $4 \%$ formaldehyde in saline) immediately after electrophysiological recordings. Brains were postfixed for at least $24 \mathrm{~h}$ ( $4 \%$ formaldehyde in saline) and cryoprotected $(25 \% \mathrm{w} / \mathrm{v}$ sucrose in PBS) until saturated and sectioned coronally $(25 \mu \mathrm{m})$ on a cryostat (Leica). Sections were mounted onto gelatin-chrom-coated slides and coverslipped with ProLong Gold Antifade Mountant (Thermo Fisher Scientific; P36930) for verification of viral reporter expression in a subset of animals. At the cessation of all other experiments, rats were decapitated and brains extracted, postfixed for at least $24 \mathrm{~h}$ ( $4 \%$ formaldehyde in saline), and cryoprotected $(25 \%$ w/v sucrose in PBS) until saturated. Next, brains were coronally sectioned $(25 \mu \mathrm{m})$ using a cryostat (Leica). Sections containing electrode or cannula tracks were mounted onto gelatin-chrom-coated slides and stained with neutral red $(0.1 \%)$ and thionin acetate $(0.01 \%)$ for histological verification of electrode tracks within the VTA or NAc or cannula/ electrode tracks within the PVT, vHipp, or NAc (Paxinos and Watson, 1998).

Statistical analysis. Electrophysiological analysis of dopamine neuron activity was performed using commercially available computer software (LabChart version 7.1; ADInstruments) and analyzed with Prism software (GraphPad Software). Data are represented as the mean \pm SEM unless otherwise stated, with $n$ values representing the number of animals per experimental group or the number of neurons per group where indicated. Statistics were calculated using SigmaPlot (Systat Software). Data were analyzed by one-way or two-way ANOVA and the HolmSidak post hoc test, with significance determined at $p<0.05$.

Materials. MAM was from Midwestern Research Institute. Chloral hydrate, NMDA, KA, DPBS, CNO (C0832), and poly I:C (P1530) were all from Sigma-Aldrich. TTX was from Tocris Bioscience. Compound 21 was from HelloBio (HB6124). Fluriso was from VetOne (502017). DREADD receptor vectors [50474: AAV2-hSyn-HA-hM3D(Gq)-mCherry; 44361: AAV-hSyn-DIO-hM3D(Gq)-mCherry] were from Addgene. The control viral vector lacking the hM3D encoding gene (rAAV2/CaMKII $\alpha$ eYFP) was from the University of North Carolina Vector Core. HSV-Cre (RN425) and control virus (RN402) were from Massachusetts General
Hospital. All other chemicals and reagents were of either analytical or laboratory grade and purchased from various suppliers.

\section{Results}

PVT activation increases dopamine neuron population activity via a hippocampal-dependent mechanism

Consistent with previous reports (Lodge and Grace, 2007; Perez and Lodge, 2012, 2013; Perez et al., 2013, 2014), control rats $(n=$ 4 rats; vHipp-vehicle) displayed an average of $0.92 \pm 0.05$ cells per track and were not affected by TTX infusion into the vHipp ( $n=4$ rats; vHipp TTX; $1.08 \pm 0.08$ cells per track; Fig. $1 A$ ). Activation of the PVT with NMDA caused a significant increase in VTA dopamine neuron population activity $(n=5$ rats; PVTNMDA; $1.87 \pm 0.0 .19$ cells per track) compared with control rats (twoway ANOVA; $F_{(1,18) \text { PVT Treatment }}=16.49 ; F_{(1,18) \text { vHipp Treatment }}=$ 5.98; $F_{(1,18) \text { Interaction }}=14.67 ;$ Holm-Sidak; $\left.p<0.001 ; t=5.48\right)$. Interestingly, the observed increase in population activity was similar to what is consistently reported following vHipp activation (Lodge and Grace, 2007) and in various rodent models of schizophrenia (Perez and Lodge, 2013; Perez et al., 2013, 2014, 2016; Aguilar et al., 2014; Boley et al., 2014). The PVT-induced increase in VTA dopamine neuron population activity was reversed by vHipp inactivation with TTX $(n=6$ rats; $1.11 \pm 0.08$ cells per track; Holm-Sidak; $p<0.001$; $t=4.82$; Fig. $1 A$ ), demonstrating that activity in the vHipp is required for the PVTinduced increase in VTA dopamine neuron population activity. It should be noted that, after vHipp inactivation, PVT activation with NMDA increased both the firing rate (PVT-NMDA: $n=40$ neurons; $4.59 \pm 0.44 \mathrm{~Hz}$; PVT-vehicle: $n=26 ; 2.60 \pm 0.47 \mathrm{~Hz}$; two-way ANOVA; $F_{(1,143) \text { PVT Treatment }}=4.47 ; F_{(1,143) \text { vHipp Treatment }}=0.06$; $F_{(1,143) \text { Interaction }}=6.27 ;$ Holm-Sidak; $p=0.001 ; t=3.26$; Fig. $\left.1 B\right)$ and percentage bursting (PVT-NMDA: $n=40$ neurons; $40.79 \pm$ 4.80\%; PVT-vehicle: $n=26 ; 27.30 \pm 4.59 \%$; two-way ANOVA; $F_{(1,143) \text { PVT }}$ Treatment $=0.38 ; F_{(1,143) \mathrm{vHipp}}$ Treatment $=0.001$; $F_{(1,143) \text { Interaction }}=4.78$; Holm-Sidak; $p=0.05 ; t=1.98 ;$ Fig. $1 C$ ) of VTA dopamine neurons. No differences were observed in the firing rates (PVT-vehicle: $n=22$ neurons; $3.78 \pm 0.35 \mathrm{~Hz}$; PVTNMDA: $n=56$ neurons; $3.61 \pm 0.32 \mathrm{~Hz}$ ) and percentage bursting (PVT-vehicle: $n=22$ neurons; $38.03 \pm 5.96 \%$; PVT-NMDA: $n=56$ neurons; $30.47 \pm 3.42 \%$ ) of vHipp-vehicle-treated rats. Cannula placements are depicted in Figure $1 D$.

\section{PVT-induced increases in dopamine transmission are attributable to glutamatergic projections to the NAc}

Next, we used the NMDA receptor antagonist KA to examine the potential glutamatergic projections contributing to the PVTinduced increase in VTA dopamine neuron activity. As reported above, control rats display a population activity of $1.00 \pm 0.05$ cells per track ( $n=7$ rats; Fig. $2 A$ ) and NMDA activation of the PVT increases in the number of cells per track $(n=7$ rats; $1.86 \pm$ 0.13 cells per track; two-way ANOVA; $F_{(2,33) \mathrm{KA}}=16.73$; $F_{(1,33) \mathrm{NMDA}}=28.27 ; F_{(2,33) \text { Interaction }}=4.88$; Holm-Sidak; $p<$ $0.001 ; t=5.54)$. Blocking glutamatergic transmission in the vHipp with KA did not reverse the increase in population activity caused by NMDA activation of the PVT $(n=5$ rats; $2.00 \pm 0.14$ cells per track; Holm-Sidak; $p<0.001 ; t=3.81$ ) compared with its respective control ( $n=6$ rats; $1.33 \pm 0.17$ cells per track), whereas inhibiting glutamate transmission in the NAc significantly attenuated (Holm-Sidak; $p<0.00 ; t=5.26$ ) the PVTinduced increase in dopamine neuron population activity $(n=5$ rats; $0.97 \pm 0.11$ cells per track; control: $n=4$ rats; $0.88 \pm 0.17$ cells per track; Fig. 2A). These data suggest that the increase in population activity caused by PVT activation is due to a glutama- 
A

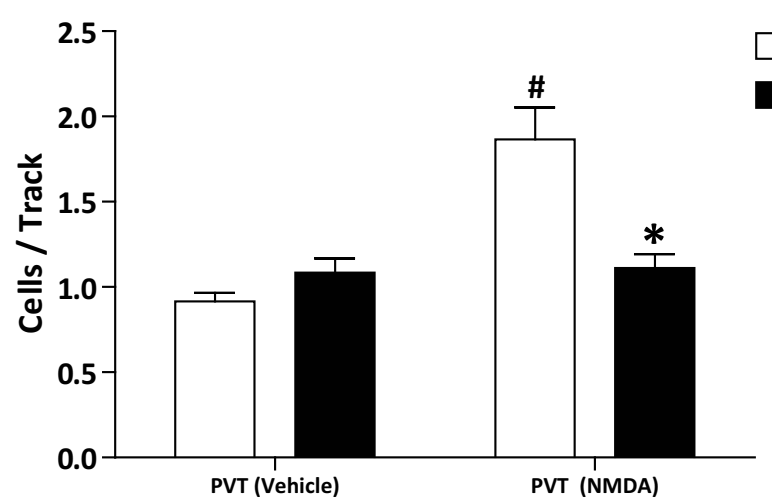

D

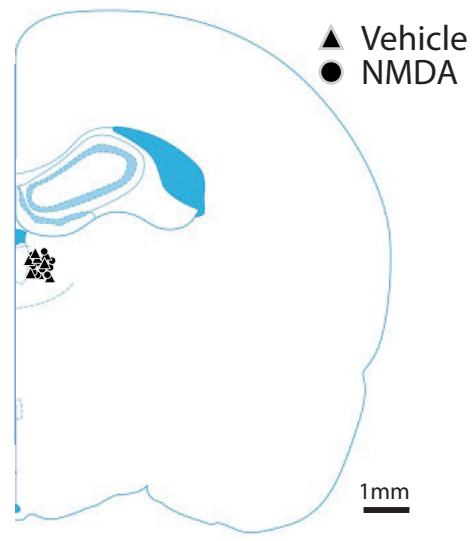

B

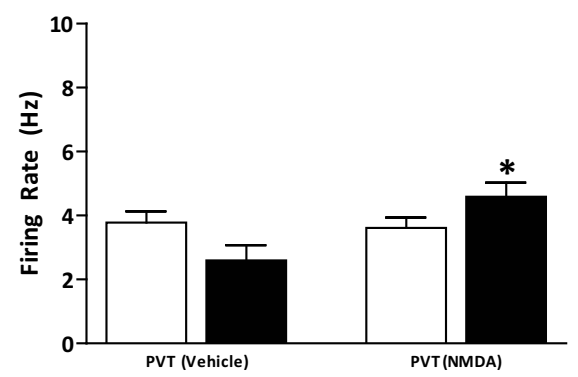

vHipp (Vehicle)

vHipp (TTX)
C

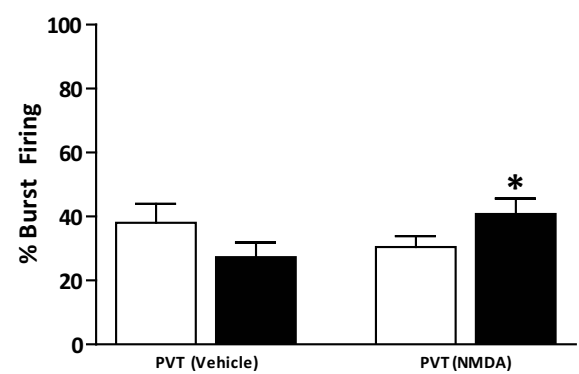

$\Delta$ Vehicle

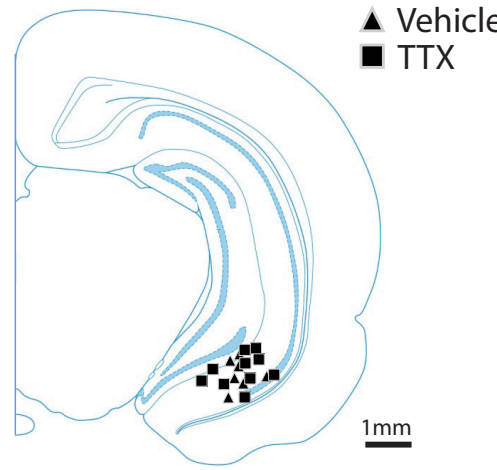

Figure 1. PVT activation increases dopamine neuron population activity via a hippocampal-dependent mechanism. Three parameters of dopamine neuron activity were measured: $(\boldsymbol{A})$ population activity (average number of spontaneously active dopamine neurons per electrode track), $(\boldsymbol{B})$ average firing rate, and $(\boldsymbol{C})$ average percentage of spikes firing in a burst. NMDA activation of the PVT produces a significant increase in VTA dopamine neuron population activity, which is reversed by TTX inactivation of the vHipp (A: * $p<0.05$ compared with PVT-NMDA/vHipp-vehicle; \#p $<$ 0.05 compared with PVT-Vehicle/vHipp-vehicle). Additionally, PVT activation significantly increased the firing rate ( $\boldsymbol{B}$ : ${ }^{*} p<0.05$ compared with PVT-vehicle/vHipp-TTX) and percentage bursting (C: ${ }^{*} p<0.05$ compared with PVT-vehicle/vHipp-TTX), but only following vHipp inactivation. $\boldsymbol{D}$, Schematic demonstrating the sites of injection adjacent to the PVT (top) and within the vHipp (bottom).

tergic projection to the NAc, not the vHipp. Consistent with the data obtained following vHipp inactivation with TTX, NMDAinduced increases in PVT activity significantly increased both firing rate and burst firing only when glutamatergic transmission was blocked in the vHipp (vehicle/PVT-vehicle: $n=42$ neurons; $4.08 \pm 0.37 \mathrm{~Hz}, 36.45 \pm 0.37 \%$; vehicle/PVT-NMDA: $n=78$ neurons; $3.27 \pm 0.29 \mathrm{~Hz}, 25.53 \pm 2.89 \%$; vHipp-KA/PVT-vehicle: $n=48$ neurons; $3.34 \pm 0.36 \mathrm{~Hz}, 32.03 \pm 3.75 \%$; vHipp-KA/ PVT-NMDA: $n=59$ neurons; $4.44 \pm 0.30 \mathrm{~Hz} ; 43.47 \pm 3.70 \%$; NAc-KA/PVT-vehicle: $n=21 ; 3.91 \pm 0.54 \mathrm{~Hz} ; 40.63 \pm 6.45 \%$; NAc-KA/PVT-NDMA: $n=29 ; 3.70 \pm 0.48 \mathrm{~Hz} ; 35.37 \pm 5.40 \%$; two-way ANOVA; firing rate: $F_{(2,276) \mathrm{vHipp} / \mathrm{NAc} \text { Treatment }}=0.20$; $F_{(1,276) \text { PVT Treatment }}=0.005 ;$ Holm-Sidak; ${ }^{\star} p=0.022 ;{ }^{\star} t=2.30$; $\# p=0.019 ; \# t=2.75$; percentage bursting: $F_{(2,276) \text { Interaction }}=$ $4.15 ; F_{(2,276) \mathrm{vHipp} / \mathrm{NAc} \text { Treatment }}=0.72 ; F_{(1,276) \mathrm{PVT} \text { Treatment }}=0.005$; $F_{(2,276) \text { Interaction }}=2.97 ;$ Holm-Sidak; ${ }^{\star} p=0.033 ;{ }^{\star} t=2.14 ; \# p=$ $0.027 ; \# t=2.63$; Fig. $2 B, C)$. Cannula placements are depicted in Figure 2D.

\section{Chemogenetic activation of the PVT-NAc, but not the PVT-mPFC, pathway increases VTA dopamine neuron population activity}

To further examine the specific PVT afferents responsible for the increase in dopamine neuron activity, we used chemogenetics (Fig. 3D). Activation of the PVT-NAc pathway by the intracranial administration of $\mathrm{CNO}$ produced a significant increase in VTA dopamine neuron activity compared with controls (Gq: $n=7$ rats; $2.37 \pm 0.23$ cells per track; control: $n=4$ rats; $0.99 \pm 0.08$ cells per track; two-way ANOVA; $F_{(1,21) \mathrm{PVT}}$ Treatment $=20.85$; $F_{(1,21) \mathrm{NAc} / \mathrm{mPFC} \text { Treatment }}=21.96 ; F_{(1,21) \text { Interaction }}=15.35 ;$ HolmSidak; $p<0.001 ; t=5.90$; Fig. $3 A$ ). Conversely, activation of the PVT-mPFC was without effect (Gq: $n=6$ rats; $0.97 \pm 0.05$ cells per track; control: $n=5$ rats; $0.87 \pm 0.06$ cells per track; Fig. $3 A$ ). No significant differences were observed in the firing rate or percentage bursting in the rats with NAc CNO (Gq: $n=95$ neurons; $3.69 \pm 0.23 \mathrm{~Hz} ; 24.86 \pm 2.47 \%$; control: $n=23$ neurons; $3.22 \pm$ $0.35 \mathrm{~Hz} ; 28.94 \pm 5.18 \%$; Fig. $3 B$ ) or mPFC CNO (Gq: $n=34$ neurons; $3.71 \pm 0.42 \mathrm{~Hz} ; 35.15 \pm 4.79 \%$; control: $n=23$ neurons; $4.09 \pm 0.61 \mathrm{~Hz} ; 30.65 \pm 5.66 \%$; Fig. $3 C$ ). Histological verification of viral reported expression is depicted in Figure $3 E$.

To further examine the projections to the NAc that regulate dopamine neuron activity, we combined a retrograde HSV-Cre with an AAV expressing the Gq-DREADD in a double-floxed inverse open reading frame that permitted the specific activation of PVT-NAc or vHipp-NAc pathways following the systemic administration of compound 21 (Fig. 4D). Control rats displayed $1.02 \pm 0.04$ cells per track, similar to what is commonly observed in normal rats (Fig. 4A). Activation of either the PVT-NAc or vHipp-NAc pathways produced a significant increase in dopamine neuron population activity (vHipp-NAc: $n=6$ rats; $1.90 \pm 0.13$ cells per track; PVT-NAc: $n=6$ rats; $1.56 \pm 0.06$ cells per track; one-way ANOVA; $F_{(1,18) \mathrm{HSV} \text { Treatment }}=44.57 ; F_{(1,18) \mathrm{PVT} / \mathrm{vHipp} \text { Treatment }}=3.31$; $F_{(1,18) \text { Interaction }}=2.04 ;$ Holm-Sidak; $p_{\mathrm{vHipp}}<0.001 ; t_{\mathrm{vHipp}}=6.01$; $p_{\mathrm{PVT}}=0.003 ; t_{\mathrm{PVT}}=3.55$; Fig. $4 A$ ). No significant differences were 

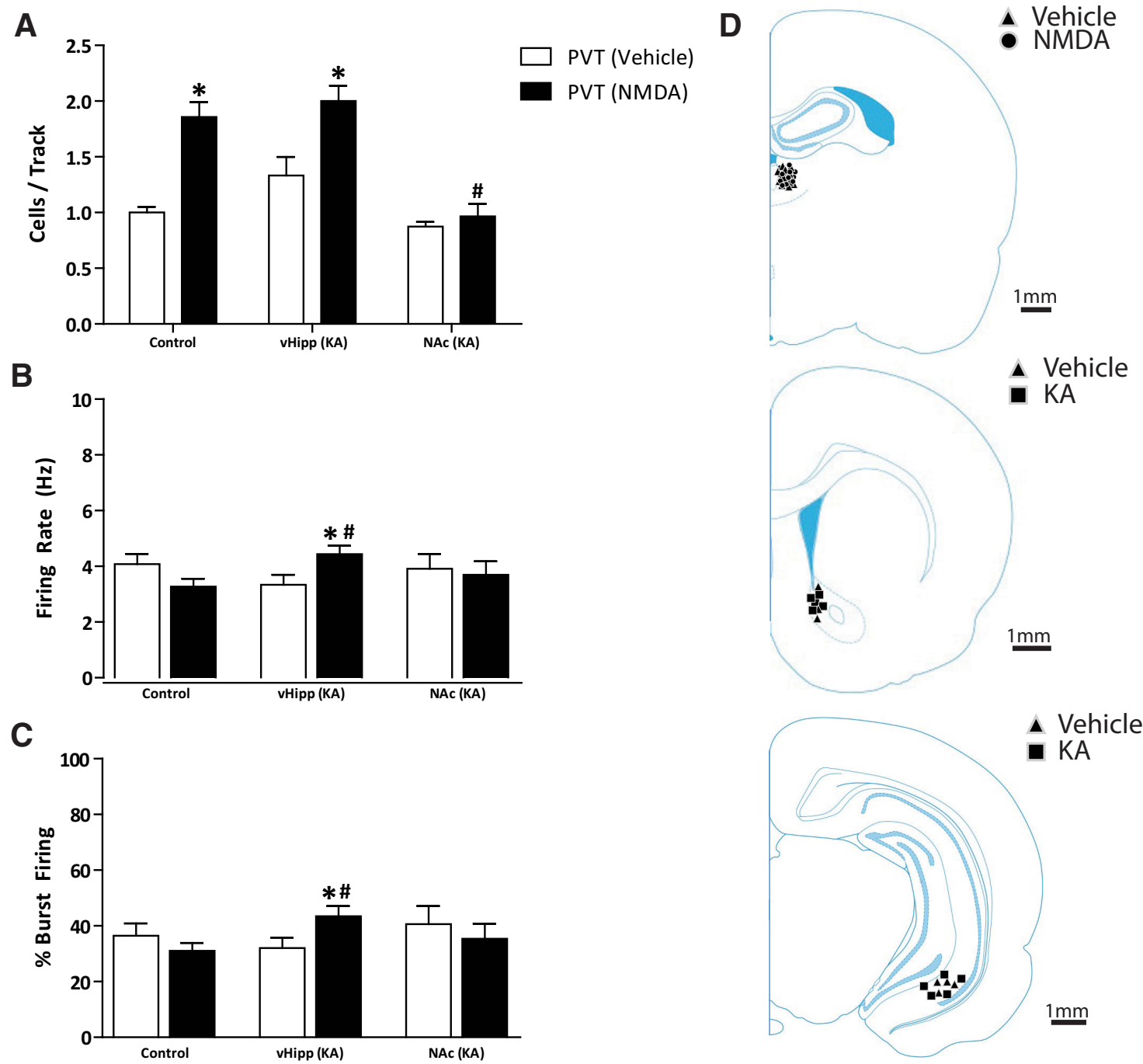

Figure 2. PVT-induced increases in dopamine neuron transmission are attributable to glutamatergic projections to the NAc. Three parameters of activity were recorded: ( $A$ ) population activity (average number of spontaneously firing dopamine neurons per electrode track), $(\boldsymbol{B})$ average firing rate, and $(\boldsymbol{C})$ average percentage spikes firing in a burst. NMDA activation of the PVT causes a significant increase in the VTA dopamine neuron population activity, which is likely caused by a glutamatergic projection in the NAc because it is attenuated by KA administration into the NAc, but not the vHipp. Following PVT activation (with NMDA), we observed significant increases in the average firing rate and percentage bursting only following glutamatergic blockade with KA in the vHipp. D, Schematic demonstrating the site of injection adjacent to the PVT (top), and within the NAc (middle), and vHipp (bottom). ${ }^{*} p<0.05$ compared with respective vehicle control. \#p $<0.05$ compared with control-vehicle/PVT-NMDA.

observed in the firing rate or percentage bursting in any of the groups [control: $n=42$ neurons; $2.87 \pm 0.48 \mathrm{~Hz} ; 39.92 \pm 24.93 \%$; vHip$\mathrm{p}(\mathrm{Gq}): n=68$ neurons; $3.95 \pm 0.32 \mathrm{~Hz} ; 36.55 \pm 3.59 \%$; PVT(Gq): $n=50$ neurons; $3.27 \pm 0.31 \mathrm{~Hz} ; 33.01 \pm 3.29 \%$; Fig. $4 B, C]$. Histological representation of recombination is depicted in Figure $4 E$.

\section{PVT activity is required for the vHipp to increase dopamine neuron activity}

Given that the NMDA activation of the PVT required activity within the vHipp, we investigated whether the converse was also true (i.e., whether PVT activity was required for the vHipp to drive an increase in the population activity of VTA dopamine neurons). Consistent with previous reports (Floresco et al., 2001, 2003; Lodge and Grace, 2006), NMDA activation of the vHipp caused a significant increase in population activity (vHipp-NMDA: $n=5$ rats; $1.63 \pm 0.08$ cells per track; vHippvehicle: $n=4$ rats; $0.92 \pm 0.05$ cells per track; two-way ANOVA; $F_{(1,18) \text { vHipp }}$ Treatment $=17.89 ; F_{(1,18) \text { Thalamus Treatment }}=9.89$; $F_{(1,18) \text { Interaction }}=25.99$; Holm-Sidak; $p<0.001 ; t=6.41$; Fig.
$5 A$ ), whereas TTX inactivation of the PVT had no effect (vHippvehicle: $n=5$ rats; $1.07 \pm 0.08$ cells per track). The vHippinduced increase in population activity was significantly attenuated by PVT inactivation with TTX (vHipp-NMDA: $n=5$ rats; $1.00 \pm 0.07$ cells per track) and is significantly different from the vHipp-NMDA control group (Holm-Sidak; $p<0.001 ; t=$ 6.01). Importantly, PVT inactivation alone did not alter dopamine neuron population activity $(n=5$ rats; $1.07 \pm 0.08$ cells per track). These data further support the hypothesis that activity in both the PVT and vHipp are required to modulate VTA dopamine neuron population activity. Again, consistent with the data depicted above, vHipp activation increased both the firing rate (vHippNMDA: $n=30$ neurons; $5.19 \pm 0.63 \mathrm{~Hz}$; vHipp-vehicle: $n=32$ neurons; $3.40 \pm 0.46 \mathrm{~Hz}$; two-way ANOVA; $F_{(1,132) \text { PVT Treatment }}=$ 9.09; $F_{(1,132) \mathrm{vHipp} \text { Treatment }}=0.03 ; F_{(1,132) \text { Interaction }}=0.39 ;$ HolmSidak; $p=0.011 ; t=2.585$; Fig. $5 B$ ) and percentage bursting (vHippNMDA: $n=30$ neurons; $49.70 \pm 5.48 \%$; vHipp-vehicle: $n=32$ neurons; $26.74 \pm 4.38 \%$; two-way ANOVA; $F_{(1,132) \text { PVT Treatment }}=$ $8.81 ; F_{(1,132) \mathrm{vHipp} \text { Treatment }}=0.50 ; F_{(1,132) \text { Interaction }}=2.18 ;$ Holm- 

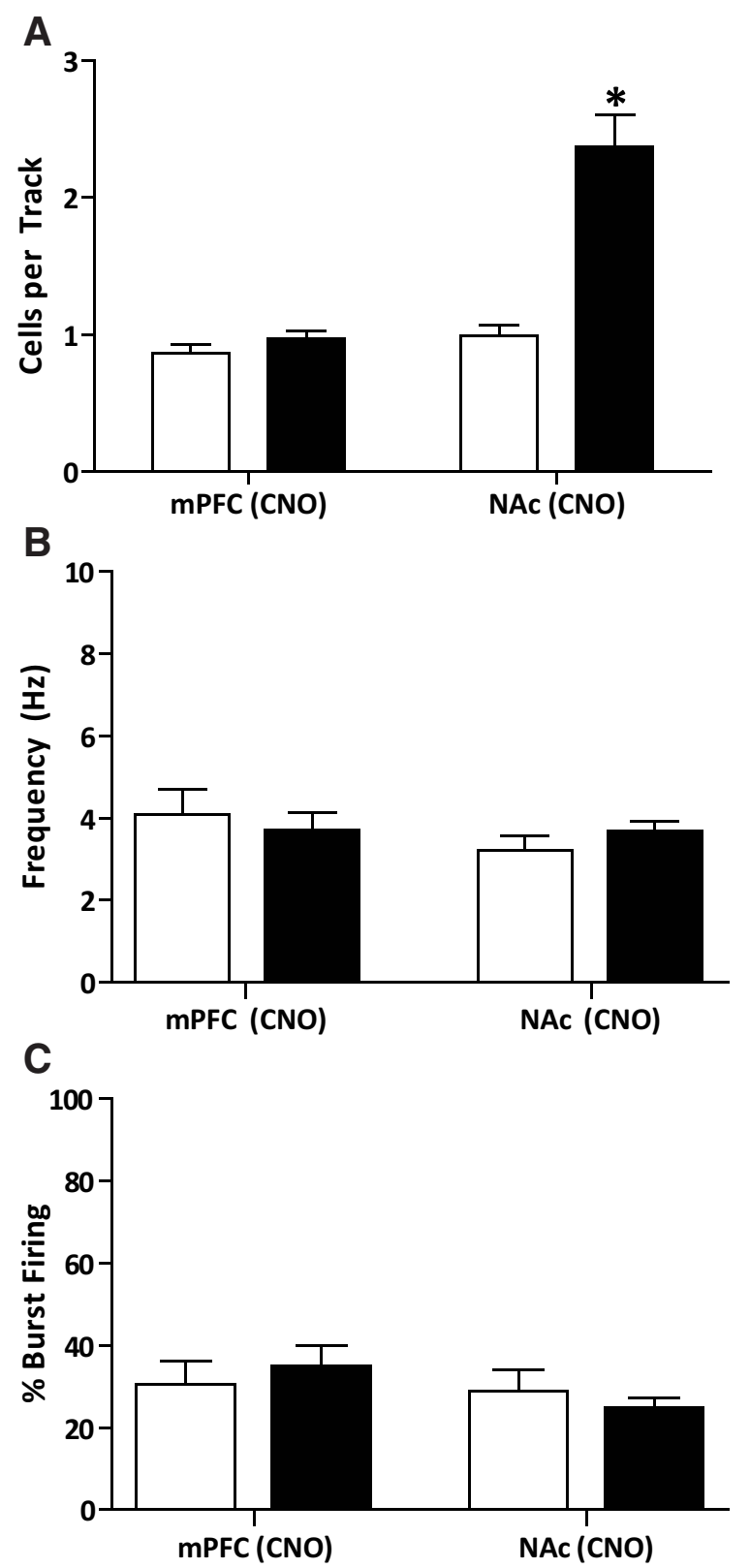
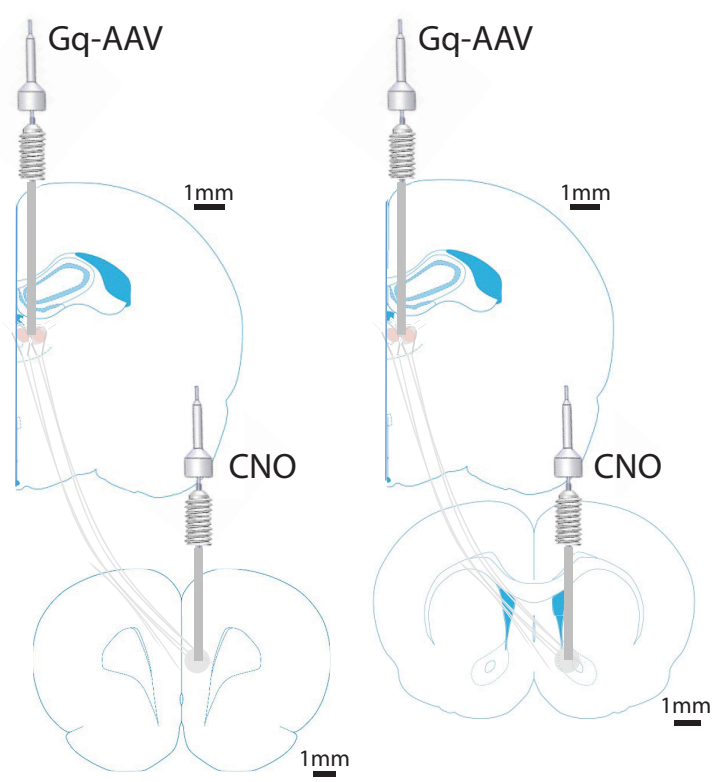

E
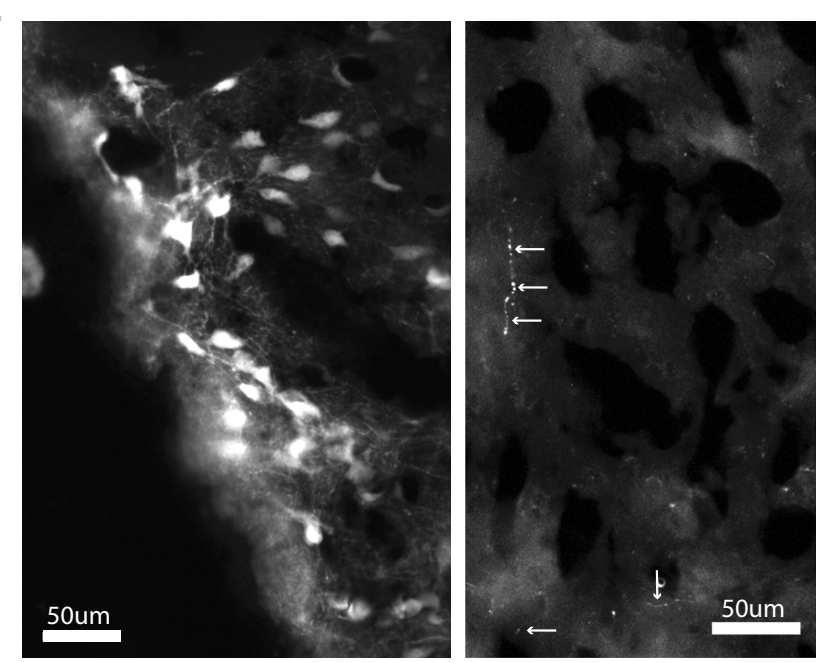

Figure 3. Chemogenetic activation of the PVT to the NAc, but not the PVT-mPFC, pathway increases VTA dopamine neuron population activity. Three parameters of activity were recorded: $(\boldsymbol{A})$ population activity (average number of spontaneously firing dopamine neurons per electrode track), $(\boldsymbol{B})$ average firing rate, and $(\boldsymbol{C})$ average percentage spikes firing in a burst. Chemogenetic activation of the PVT-NAc pathway causes a significant increase in VTA dopamine neuron population activity. In contrast, activation of the PVT-mPFC pathway did not affect VTA dopamine neuron population activity. D, Schematic representation of the viral injection (AAV-Gq-DREADD) to the PVT and stainless steel cannula used to target the mPFC or NAC (for CNO administration). $\boldsymbol{E}$, Histological verification of viral reporter expression demonstrating cell bodies in the PVT (left) and terminals in afferent targets in the mPFC (right). ${ }^{*} p<0.05$ compared with control.

Sidak; $p=0.002 ; t=3.16$; Fig. $5 C$ ) of VTA dopamine neurons, but only after PVT inactivation. No other differences were observed in the firing rates (vHipp-vehicle: $n=22$ neurons; $3.78 \pm 0.35 \mathrm{~Hz}$; vHipp-NMDA: $n=49$ neurons; $4.96 \pm 0.38$ $\mathrm{Hz}$ ) or percentage bursting (vHipp-vehicle: $n=22$ neurons; $38.03 \pm 5.96 \%$; vHipp-NMDA: $n=49$ neurons; $45.74 \pm$ $4.33 \%)$ of PVT-vehicle-treated rats. Cannula placements are depicted in Figure 5D.

\section{NAc receives convergent inputs from the PVT and vHipp}

To verify that medium spiny neurons of the NAc receive convergent inputs from both the vHipp and PVT, we performed in vivo extracellular recordings from these neurons (representative evoked responses are depicted in Fig. 6B). Average spike latencies for putative medium spiny neurons are $17.21 \pm 3.43 \mathrm{~ms}(n=100$ evoked action potentials) when responding to PVT stimulation and $11.54 \pm 0.36 \mathrm{~ms}(n=100$ evoked action potentials $)$ when responding to vHipp stimulation. A total of 48 neurons were recorded from the NAc, with $29 \%$ responding only to stimulation from the PVT, 35\% responding only to stimulation from the vHipp, and 36\% responding to stimulation from both structures (Fig. 6C). These data demonstrate that a significant proportion of medium spiny neurons within the NAc do indeed receive convergent inputs from the PVT and vHipp. Electrode placements are depicted in Figure $6 \mathrm{~A}$. 

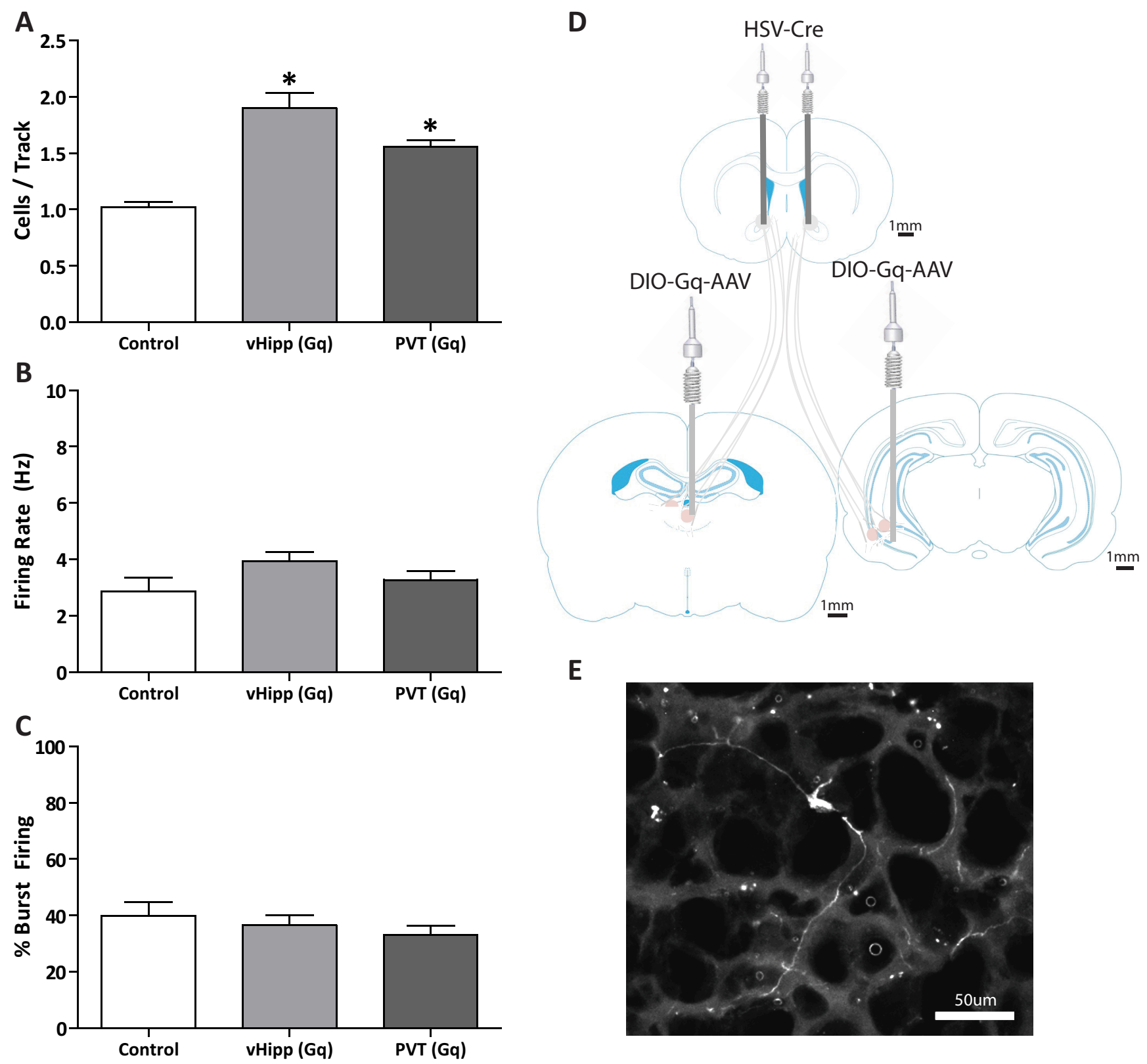

Figure 4. Chemogenetic activation of the pathways from the vHipp and the PVT to the NAc produce increases in VTA dopamine neuron population activity. Three parameters of activity were recorded: $(\boldsymbol{A})$ population activity (average number of spontaneously firing dopamine neurons per electrode track), $(\boldsymbol{B})$ average firing rate, and $(\boldsymbol{C})$ average percentage spikes firing in a burst. Consistent with previous reports, activation of the vHipp-NAc pathway produces a significant increase in VTA dopamine neuron population activity. Here we demonstrate that activation of the PVT-NAc pathway produces a similar effect on dopamine neuron activity. D, Schematic representation of the bilateral viral injections to the vHipp or PVT (AAV-DIO-Gq-DREADD) and NAC (HSV-Cre). $\boldsymbol{E}$, Histological verification of viral reported expression demonstrating a NAc-projecting neuron in the PVT. ${ }^{*} p<0.05$ compared with control.

PVT inactivation reverses aberrant dopamine neuron activity in two different rodent models of schizophrenia

We have previously demonstrated that rodent models of schizophrenia display increases in dopamine neuron population activity (Perez and Lodge, 2013; Perez et al., 2013, 2014, 2016; Aguilar et al., 2014; Boley et al., 2014), which has been attributable to increases in vHipp activity because it is reversed by inactivation of the vHipp (Lodge and Grace, 2007). This observation has led to the suggestion that the vHipp may be a novel therapeutic target for schizophrenia (for review, see Perez and Lodge, 2014). Based on the data detailed above, it is likely that PVT manipulations may also be an effective approach to treat the aberrant dopamine system function. Here, we examine the effects of PVT inactivation (using TTX) on the aberrant dopamine neuron activity ob- served in two different rodent models of schizophrenia. As discussed above, control rats display a population activity of $1.00 \pm 0.05$ cells per track $(n=7$ rats; Fig. $7 A)$. TTX inactivation of the PVT had no effect on population activity in control rats ( $n=5$ rats; $1.07 \pm 0.08$ cells per track). MAM-treated rats $(n=7$ rats; $1.85 \pm 0.12$ cells per track) and poly I:C-treated rats $(n=6$ rats; $1.64 \pm 0.13$ cells per track) exhibited significantly higher population activities compared with vehicle controls (two-way ANOVA; $F_{(2,37) \text { PVT Treatment }}=17.78 ; F_{(1,37) \text { vHipp Treatment }}=18.53$; $F_{(2,37) \text { Interaction }}=6.61$; Holm-Sidak; MAM: $p<0.001 ; t=6.45$; poly I:C: $p<0.001 ; t=4.65)$ and were significantly attenuated by PVT inactivation (MAM: $n=7$ rats; $1.38 \pm 0.10$ cells per track; Holm-Sidak; $p=0.001 ; t=3.57$; poly I:C: $n=6$ rats; $1.00 \pm 0.06$ cells per track; Holm-Sidak; $p<0.001 ; t=4.48$ ). Therefore, 
A

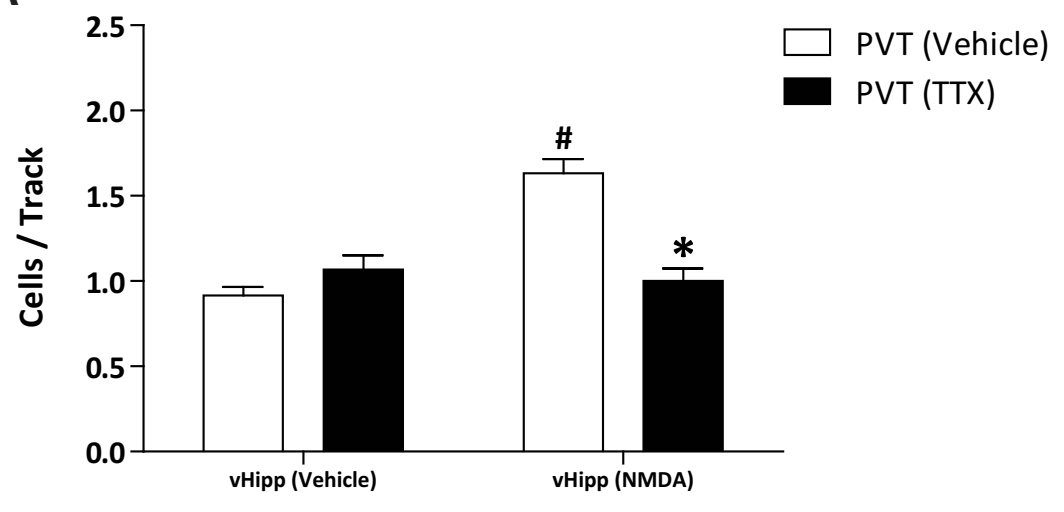

D

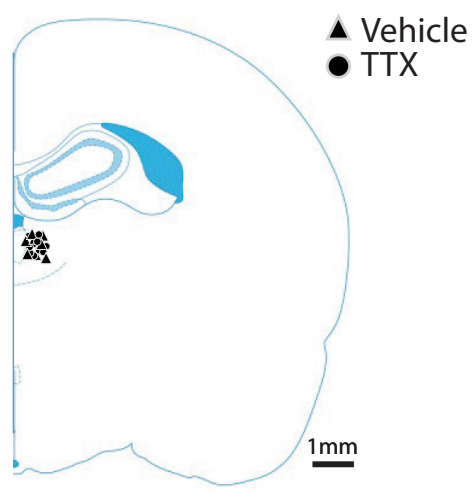

B

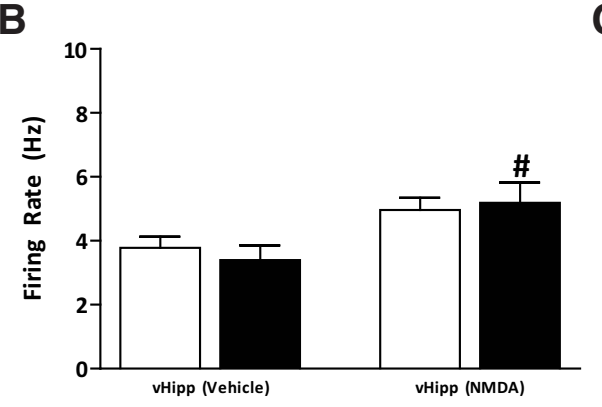

C

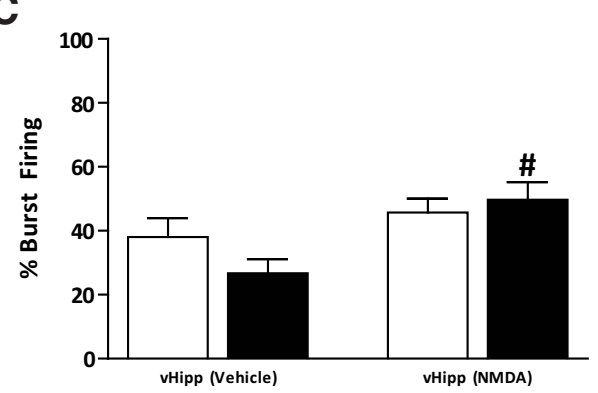

$\Delta$ Vehicle

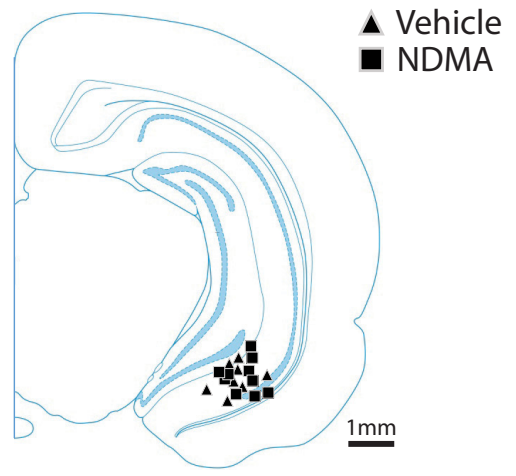

Figure 5. PVT activity is required for the vHipp to increase dopamine neuron activity. Three parameters of activity were recorded: $(A)$ population activity (average number of spontaneously firing dopamine neurons per electrode track), $(\boldsymbol{B})$ average firing rate, and $(\boldsymbol{C}$ ) and average percentage spikes firing in a burst. NMDA activation of the vHipp causes a significant increase in VTA dopamine neuron population activity, which is attenuated by TTX inactivation of the PVT. Additionally, vHipp activation significantly increased the firing rate and percentage bursting, but only following TTX inactivation of the PVT. D, Schematic demonstrating the site of injection within the PVT (top) and vHipp (bottom). ${ }^{*} p<0.05$ compared with vHipp-NMDA/PVT-vehicle. \#p $<0.05$ compared with PVT-vehicle/vHipp-vehicle.

pharmacological inactivation of the PVT is sufficient to restore dopamine system function in two rodent models of schizophrenia, suggesting that this region may be a novel site of intervention for the disease. No differences were observed in firing rates (Fig. $7 B$ ) or percentage bursting (Fig. 7C) between any of the groups (control vehicle: $n=22$ neurons; $3.78 \pm 0.35 \mathrm{~Hz} ; 38.03 \pm 5.96 \%$; control TTX: $n=32$ neurons; $3.40 \pm 0.46 \mathrm{~Hz} ; 26.74 \pm 4.38 \%$; MAM-vehicle: $n=76$ neurons; $4.46 \pm 0.25 \mathrm{~Hz} ; 37.21 \pm 2.30 \%$; MAM-TTX: $n=56$ neurons; $4.40 \pm 0.29 \mathrm{~Hz} ; 40.14 \pm 4.01 \%$; poly I:C-vehicle: $n=59$ neurons; $3.98 \pm 0.30 \mathrm{~Hz} ; 36.29 \pm 3.88 \%$; poly I:C-TTX: $n=36$ neurons; $3.44 \pm 0.43 \mathrm{~Hz} ; 31.62 \pm 4.08 \%$ ) Cannula placements are depicted in Figure $7 D$.

\section{Discussion}

Individuals with schizophrenia exhibit enhanced hippocampal activity at baseline, which has been correlated with positive symptom severity (Schobel et al., 2009). Similarly, various rodent models display a similar increase in vHipp activity, as measured by electrophysiology (Lodge and Grace, 2007; Perez and Lodge, 2013; Shah and Lodge, 2013; Boley et al., 2014). Increases in glutamatergic transmission from the vHipp to the NAc augment GABAergic neurotransmission to the ventral pallidum, disinhibiting VTA dopamine neurons (Floresco et al., 2001) (Fig. 8). We have consistently demonstrated that augmented hippocampal activity underlies aberrant dopamine system function in rodent models of schizophrenia (Lodge and Grace, 2007; Perez and Lodge, 2013; Perez et al., 2013, 2016). Further, the hippocampus has been advanced as a novel therapeutic target to treat positive, negative and cognitive symptoms (for review, see Perez and Lodge, 2014).

As detailed above, recent postmortem studies in individuals with schizophrenia have reported aberrant vGlut2 expression in the NAc (McCollum and Roberts, 2015). Although the hippocampus does express low levels of this transporter (Fremeau et al., 2001), it is more likely that these reported differences are attributable to altered input from the thalamus. There is a significant literature demonstrating alterations in thalamic structure and function in schizophrenia; however, how this pathology contributes to the development or symptoms of schizophrenia has not been elucidated. The thalamus is an integrative structure that serves as a point of convergence for several neuronal circuits (Andreasen et al., 1994; Byne et al., 2009). The volume of the thalamus is consistently reported to be decreased in individuals with schizophrenia (Gilbert et al., 2001; McDonald et al., 2005; Byne et al., 2009), whereas functional imaging studies have reported both increases and decreases in thalamic activation in individuals with schizophrenia (for review, see Pergola et al., 2015). However, whether these thalamic abnormalities contribute to the aberrant regulation of dopamine system function (thought to underlie the positive symptoms of schizophrenia) has not been demonstrated. Here, we investigate the thalamic regulation of VTA dopamine neuron activity in both the normal rat and in pathological rodent models of schizophrenia.

The thalamus is composed of multiple nuclei, each with their own distinct afferent and efferent projections. Studies have 
A
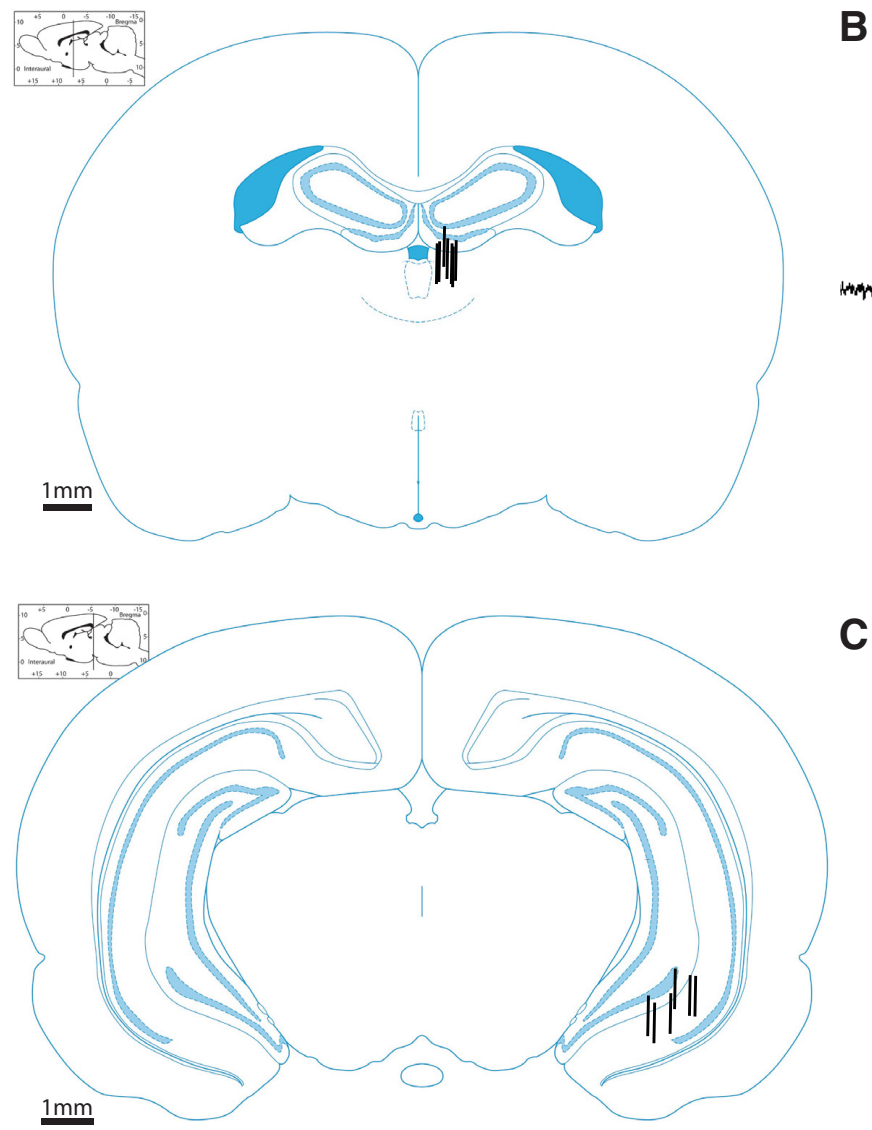

B

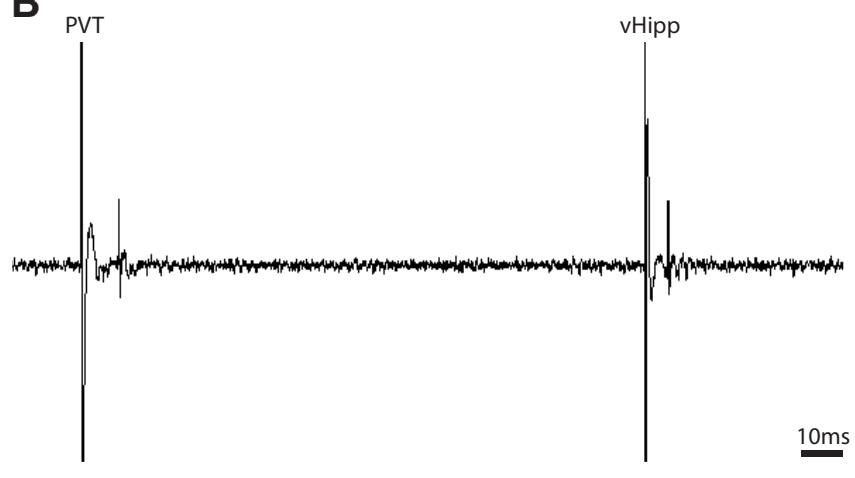

C

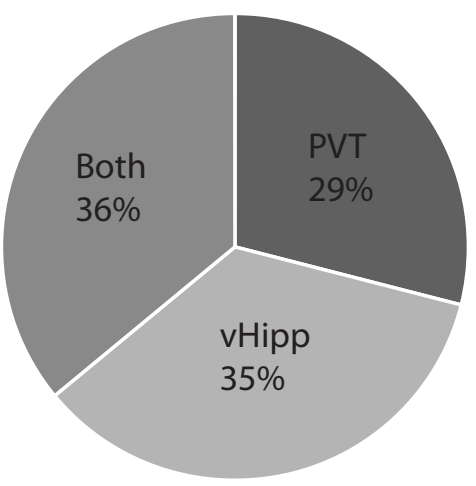

Figure 6. The NAc receives convergent input from the PVT and the vHipp. $\boldsymbol{A}$, Schematic demonstrating the sites of stimulation adjacent to the PVT (top) and within vHipp (bottom). $\boldsymbol{B}$, Representative trace from a putative medium spiny neuron responding to stimulation from the PVT and vHipp. C, Percentage of cells that responded to stimulation from the PVT, vHipp, or both.

A

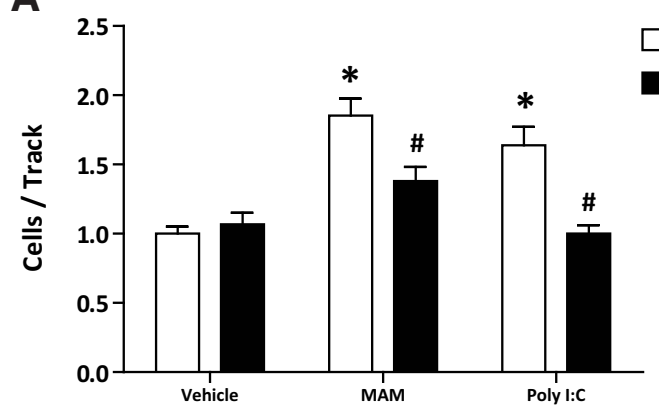

C

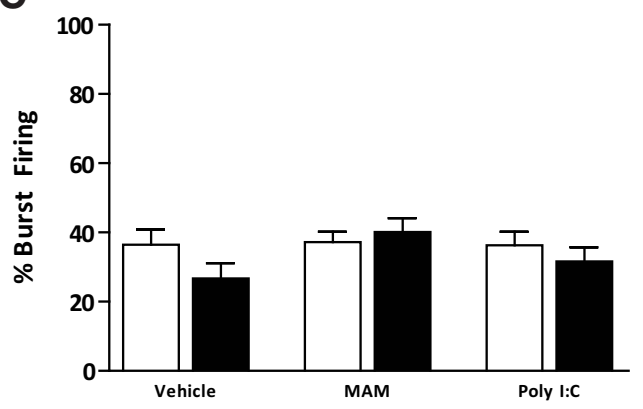

B

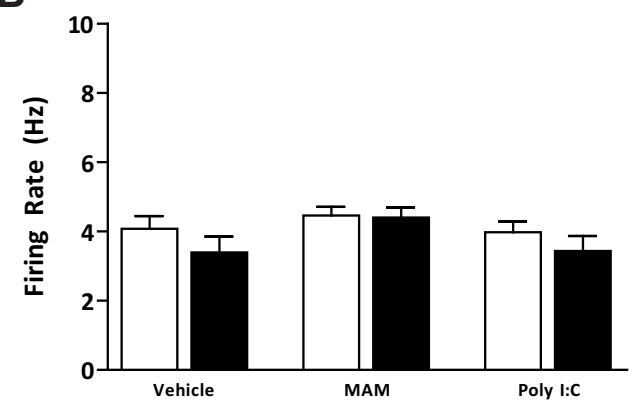

D

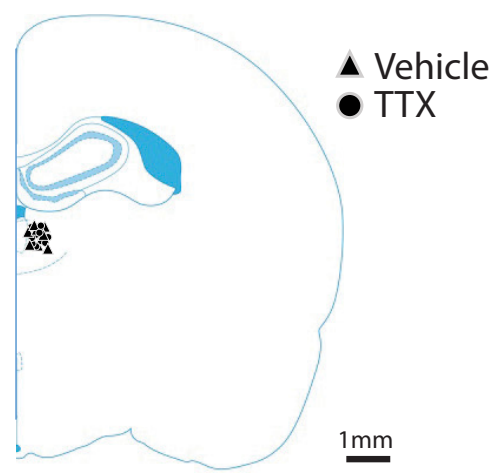

Figure 7. Inactivation of the PVT attenuates aberrant dopamine neuron activity in two different rodent models of schizophrenia. Three parameters of activity were recorded: $(\boldsymbol{A})$ population activity (average number of spontaneously firing dopamine neurons per electrode track), $(\boldsymbol{B})$ average firing rate, and $(\boldsymbol{C})$ average percentage spikes firing in a burst. The MAM and poly $\mathrm{l}: \mathrm{C}$ rodent models of schizophrenia display a significant increase in VTA dopamine neuron population activity, which is attenuated by TTX inactivation of the PVT. D, Schematic demonstrating the site of injection adjacent to the PVT. ${ }^{*} p<0.05$ compared with Prenatal-vehicle. $\# p<0.05$ compared with PVT-vehicle. 
shown that the reunions nucleus of the thalamus (RE) is able to modulate VTA dopamine activity via activation of the vHipp or via a polysynaptic circuit involving the RE-mPFC-vHipp (Lisman et al., 2010; Zimmerman and Grace, 2016). However, of importance to this study is the role of the PVT because studies have demonstrated that the PVT provides the predominate thalamic innervation of the NAc (Su and Bentivoglio, 1990; Bubser and Deutch, 1998; Pinto et al., 2003; Dong et al., 2017). Using in vivo electrophysiology, we now demonstrate that pharmacological activation of the PVT induces increases in VTA dopamine neuron population activity. The term "population activity" is based on the observation that a number of dopamine neurons $(\sim 50 \%)$ are not spontaneously active in vivo. These "silent" neurons are hyperpolarized due to a tonic GABAergic input from the ventral pallidum (Lodge and Grace, 2011). The role of these silent dopamine neurons appears critical because they provide a gain of function to the dopamine signal. Specifically, by regulating the number of spontaneously active dopamine neurons, one can manipulate the magnitude of the dopamine signal (both tonic and phasic). Therefore, the PVT may regulate the number of spontaneously active dopamine neurons without significantly affecting firing rate or pattern. This is identical to previous reports examining hippocampal regulation of the VTA, in which vHipp activation produces selective increases in dopamine neuron population activity (Lodge and Grace, 2007). Indeed, this is what we observed: pharmacological activation of the PVT (with NMDA) was sufficient to induce a significant increase in VTA dopamine neuron population activity (Fig. 1). To determine whether activity in the vHipp contributed to the PVT-induced increase in dopamine neuron activity, we inactivated the vHipp by intracranial administration of the $\mathrm{Na}^{+}$-channel blocker TTX, which completely prevented the increase in dopamine neuron population activity induced by PVT activation. Interestingly, we also demonstrate that PVT activation was able to increase firing rate and burst firing of midbrain dopamine neurons; however, this was only observed following inactivation of the vHipp (Figs. 1, 2). This further demonstrates the dissociation between the afferent control of dopamine neuron population activity and firing rate/burst firing (Floresco et al., 2003); however, it is unclear whether PVT or adjacent thalamic projections contributed to this observation and why they were only observed following vHipp inactivation.

To determine whether the PVT-induced increase in dopamine neuron activity was due to a glutamatergic projection to the vHipp, we blocked glutamatergic (NMDA) transmission by administering KA into the vHipp. Interestingly, this did not alter the response to PVT activation, suggesting that a glutamatergic projection to the vHipp does not contribute to the observed increase in population activity (Fig. 2). It has been previously demonstrated that vHipp activation of the VTA occurs via a glutamatergic projection to the NAc (Floresco et al., 2001). Given the extensive innervation of the NAc from the PVT, we examined the role of this pathway. We now demonstrate that the PVTinduced increase in dopamine neuron population activity is attributable to a glutamatergic projection to the NAc because administration of KA in this region was sufficient to block any increase in dopamine neuron population activity.

To demonstrate conclusively that the PVT-NAc pathway can modulate dopamine neuron activity, we performed two different chemogenetic studies. First, we expressed Gq-DREADD in the PVT and microinjected CNO into the mPFC or NAc to specifically activate PVT terminals present in these regions (Fig. 3). We did not observe an increase in population activity when we selectively activated PVT-mPFC projections, suggesting that this pathway is not involved in the observed increase in population activity following PVT activation. However, activation of the PVT-NAc pathway produced a similar increase in dopamine neuron population activity, providing further evidence for this pathway in the PVT regulation of dopamine neuron activity. Next, we injected a DIO-Gq-DREADD into either the vHipp or PVT in combination with a retrograde HSV-Cre into the NAc. Following this approach, we again demonstrate that activation of vHipp or PVT inputs to the NAc selectively increase dopamine neuron population activity (Fig. 4).

Given that activity in the vHipp was required for the PVTinduced increase in dopamine neuron activity, we investigated whether the converse was also true. We pharmacologically inactivated the PVT with TTX following NMDA activation of the vHipp (Fig. 5). Interestingly, vHipp activation induced an increase in dopamine neuron population activity that was significantly attenuated by PVT inactivation. These data suggest that the NAc receives convergent inputs from the vHipp and PVT that work in concert to regulate VTA dopamine neuron activity. To determine whether individual neurons in the NAc receive convergent input from the PVT and vHipp, we performed in vivo extracellular recordings from putative medium spiny neurons of the NAc (Fig. 6). We observed that a significant proportion of these cells do indeed receive convergent input from the vHipp and PVT. Previous electrophysiological studies have demonstrated that NAc medium spiny neurons exhibit a bistable membrane potential alternating between the so-called UP $(\sim-60$ $\mathrm{mV}$ ) and DOWN $(\sim-75 \mathrm{mV})$ states (O'Donnell and Grace, 1995; Goto and O'Donnell, 2001). It is only when these cells are in an UP state (i.e., have a depolarized membrane potential) that they are able to fire action potentials in response to afferent input (O'Donnell and Grace, 1995). Interestingly, these UP states have been attributed to vHipp activation because they can be induced 
by stimulation of the fornix and are abolished by lidocaine inactivation of hippocampal afferents (O'Donnell and Grace, 1995). Therefore, we posit that vHipp afferents to the NAc are required to generate an UP state and that PVT afferents drive spike firing. This would explain why activity in both regions is required to induce downstream alterations in dopamine system function (Fig. 8).

The data detailed above suggest that the PVT may be a novel site of intervention for psychosis by reversing aberrant dopamine neuron population activity. Indeed, we now demonstrate that the aberrant dopamine system function observed in two distinct rodent models displaying circuit level alterations and corresponding behavioral deficits relevant to schizophrenia (MAM and poly I:C) was normalized by pharmacological inactivation of the PVT (Fig. 7).

We have demonstrated that both the vHipp and PVT play a role in the regulation of VTA dopamine neuron activity via convergent glutamatergic inputs to the NAc. Additionally, the increases in dopamine neuron population activity exhibited by various rodent models of the disease are not just reversed by vHipp inactivation (Lodge and Grace, 2007), but also by inactivation of the PVT, further suggesting that these two regions work together to regulate dopamine neuron activity. This study provides evidence of the PVT as a potential site of pathology in schizophrenia and should be investigated as a possible site of therapeutic intervention.

\section{References}

Abi-Dargham A (2004) Do we still believe in the dopamine hypothesis? New data bring new evidence. Int J Neuropsychopharmacol 7:S1-S5. CrossRef Medline

Aguilar DD, Chen L, Lodge DJ (2014) Increasing endocannabinoid levels in the ventral pallidum restores aberrant dopamine neuron activity in the subchronic PCP rodent model of schizophrenia. Int J Neuropsychopharmacol 18:pii: pyu035. CrossRef Medline

Alexander GM, Rogan SC, Abbas AI, Armbruster BN, Pei Y, Allen JA, Nonneman RJ, Hartmann J, Moy SS, Nicolelis MA, McNamara JO, Roth BL (2009) Remote control of neuronal activity in transgenic mice expressing evolved G protein-coupled receptors. Neuron 63:27-39. CrossRef Medline

Andreasen NC, Arndt S, Swayze V 2nd, Cizadlo T, Flaum M, O’Leary D, Ehrhardt JC, Yuh WT (1994) Thalamic abnormalities in schizophrenia visualized through magnetic resonance image averaging. Science 266: 294-298. CrossRef Medline

Bellocchio EE, Reimer RJ, Fremeau RT Jr, Edwards RH (2000) Uptake of glutamate into synaptic vesicles by an inorganic phosphate transporter. Science 289:957-960. CrossRef Medline

Boley AM, Perez SM, Lodge DJ (2014) A fundamental role for hippocampal parvalbumin in the dopamine hyperfunction associated with schizophrenia. Schizophr Res 157:238-243. CrossRef Medline

Bubser M, Deutch AY (1998) Thalamic paraventricular nucleus neurons collateralize to innervate the prefrontal cortex and nucleus accumbens. Brain Res 787:304-310. CrossRef Medline

Byne W, Hazlett EA, Buchsbaum MS, Kemether E (2009) The thalamus and schizophrenia: current status of research. Acta Neuropathol 117:347-368. CrossRef Medline

Chen X, Choo H, Huang XP, Yang X, Stone O, Roth BL, Jin J (2015) The first structure-activity relationship studies for designer receptors exclusively activated by designer drugs. ACS Chem Neurosci 6:476-484. CrossRef Medline

Clinton SM, Meador-Woodruff JH (2004) Thalamic dysfunction in schizophrenia: neurochemical, neuropathological, and in vivo imaging abnormalities. Schizophr Res 69:237-253. CrossRef Medline

Dong X, Li S, Kirouac GJ (2017) Collateralization of projections from the paraventricular nucleus of the thalamus to the nucleus accumbens, bed nucleus of the stria terminalis, and central nucleus of the amygdala. Brain Struct Funct 222:3927-3943. CrossRef Medline

Floresco SB, Todd CL, Grace AA (2001) Glutamatergic afferents from the hippocampus to the nucleus accumbens regulate activity of ventral tegmental area dopamine neurons. J Neurosci 21:4915-4922. CrossRef Medline

Floresco SB, West AR, Ash B, Moore H, Grace AA (2003) Afferent modulation of dopamine neuron firing differentially regulates tonic and phasic dopamine transmission. Nat Neurosci 6:968-973. CrossRef Medline

Fremeau RT Jr, Troyer MD, Pahner I, Nygaard GO, Tran CH, Reimer RJ, Bellocchio EE, Fortin D, Storm-Mathisen J, Edwards RH (2001) The expression of vesicular glutamate transporters defines two classes of excitatory synapse. Neuron 31:247-260. CrossRef Medline

Gilbert AR, Rosenberg DR, Harenski K, Spencer S, Sweeney JA, Keshavan MS (2001) Thalamic volumes in patients with first-episode schizophrenia. Am J Psychiatry 158:618-624. CrossRef Medline

Goto Y, O'Donnell P (2001) Network synchrony in the nucleus accumbens in vivo. J Neurosci 21:4498-4504. CrossRef Medline

Grace AA, Bunney BS (1983) Intracellular and extracellular electrophysiology of nigral dopaminergic neurons. 1. Identification and characterization. Neuroscience 10:301-315. CrossRef Medline

Guettier JM, Gautam D, Scarselli M, Ruiz de Azua I, Li JH, Rosemond E, Ma X, Gonzalez FJ, Armbruster BN, Lu H, Roth BL, Wess J (2009) A chemical-genetic approach to study $\mathrm{G}$ protein regulation of beta cell function in vivo. Proc Natl Acad Sci U S A 106:19197-19202. CrossRef Medline

Heckers S (2001) Neuroimaging studies of the hippocampus in schizophrenia. Hippocampus 11:520-528. CrossRef Medline

Hisano S, Hoshi K, Ikeda Y, Maruyama D, Kanemoto M, Ichijo H, Kojima I, Takeda J, Nogami H (2000) Regional expression of a gene encoding a neuron-specific $\mathrm{Na}(+)$-dependent inorganic phosphate cotransporter (DNPI) in the rat forebrain. Brain Res Mol Brain Res 83:34-43. CrossRef Medline

Hyland BI, Reynolds JN, Hay J, Perk CG, Miller R (2002) Firing modes of midbrain dopamine cells in the freely moving rat. Neuroscience 114:475492. CrossRef Medline

Javitt DC (2009) When doors of perception close: bottom-up models of disrupted cognition in schizophrenia. Annu Rev Clin Psychol 5:249-275. CrossRef Medline

Laruelle M, Abi-Dargham A (1999) Dopamine as the wind of the psychotic fire: new evidence from brain imaging studies. J Psychopharmacol 13: 358-371. CrossRef Medline

Lewis DA, Pierri JN, Volk DW, Melchitzky DS, Woo TU (1999) Altered GABA neurotransmission and prefrontal cortical dysfunction in schizophrenia. Biol Psychiatry 46:616-626. CrossRef Medline

Lewis DA, Hashimoto T, Volk DW (2005) Cortical inhibitory neurons and schizophrenia. Nat Rev Neurosci 6:312-324. CrossRef Medline

Lisman JE, Pi HJ, Zhang Y, Otmakhova NA (2010) A thalamo-hippocampalventral tegmental area loop may produce the positive feedback that underlies the psychotic break in schizophrenia. Biol Psychiatry 68:17-24. CrossRef Medline

Lodge DJ (2013) The MAM rodent model of schizophrenia. Curr Protoc Neurosci 63:9.43.1-9.43.7. CrossRef

Lodge DJ, Grace AA (2006) The hippocampus modulates dopamine neuron responsivity by regulating the intensity of phasic neuron activation. Neuropsychopharmacology 31:1356-1361. CrossRef Medline

Lodge DJ, Grace AA (2007) Aberrant hippocampal activity underlies the dopamine dysregulation in an animal model of schizophrenia. J Neurosci 27:11424-11430. CrossRef Medline

Lodge DJ, Grace AA (2011) Hippocampal dysregulation of dopamine system function and the pathophysiology of schizophrenia. Trends Pharmacol Sci 32:507-513. CrossRef Medline

MacLaren DA, Browne RW, Shaw JK, Krishnan Radhakrishnan S, Khare P, Espana RA, Clark SD (2016) Clozapine N-oxide administration produces behavioral effects in Long-Evans rats: implications for designing DREADD experiments. eNeuro 3. CrossRef Medline

McCollum LA, Roberts RC (2015) Uncovering the role of the nucleus accumbens in schizophrenia: a postmortem analysis of tyrosine hydroxylase and vesicular glutamate transporters. Schizophr Res 169:369-373. CrossRef Medline

McDonald C, Bullmore E, Sham P, Chitnis X, Suckling J, MacCabe J, Walshe M, Murray RM (2005) Regional volume deviations of brain structure in schizophrenia and psychotic bipolar disorder: computational morphometry study. Br J Psychiatry 186:369-377. CrossRef Medline

Moghaddam B, Javitt D (2012) From revolution to evolution: the glutamate 
hypothesis of schizophrenia and its implication for treatment. Neuropsychopharmacology 37:4-15. CrossRef Medline

Moore H, Jentsch JD, Ghajarnia M, Geyer MA, Grace AA (2006) A neurobehavioral systems analysis of adult rats exposed to methylazoxymethanol acetate on E17: implications for the neuropathology of schizophrenia. Biol Psychiatry 60:253-264. CrossRef Medline

O’Donnell P, Grace AA (1995) Synaptic interactions among excitatory afferents to nucleus accumbens neurons: hippocampal gating of prefrontal cortical input. J Neurosci 15:3622-3639. CrossRef Medline

Oke AF, Adams RN (1987) Elevated thalamic dopamine: possible link to sensory dysfunctions in schizophrenia. Schizophr Bull 13:589-604. CrossRef Medline

Paxinos G, Watson C (1998) The rat brain in stereotaxic coordinates. San Diego: Academic.

Perez SM, Lodge DJ (2012) Aberrant dopamine D2-like receptor function in a rodent model of schizophrenia. J Pharmacol Exp Ther 343:288-295. CrossRef Medline

Perez SM, Lodge DJ (2013) Hippocampal interneuron transplants reverse aberrant dopamine system function and behavior in a rodent model of schizophrenia. Mol Psychiatry 18:1193-1198. CrossRef Medline

Perez SM, Lodge DJ (2014) New approaches to the management of schizophrenia: focus on aberrant hippocampal drive of dopamine pathways. Drug Des Devel Ther 8:887-896. CrossRef Medline

Perez SM, Shah A, Asher A, Lodge DJ (2013) Hippocampal deep brain stimulation reverses physiological and behavioural deficits in a rodent model of schizophrenia. Int J Neuropsychopharmacol 16:1331-1339. CrossRef Medline

Perez SM, Carreno FR, Frazer A, Lodge DJ (2014) Vagal nerve stimulation reverses aberrant dopamine system function in the methylazoxymethanol acetate rodent model of schizophrenia. J Neurosci 34:9261-9267. CrossRef Medline

Perez SM, Aguilar DD, Neary JL, Carless MA, Giuffrida A, Lodge DJ (2016)
Schizophrenia-like phenotype inherited by the F2 generation of a gestational disruption model of schizophrenia. Neuropsychopharmacology 41:477-486. CrossRef Medline

Pergola G, Selvaggi P, Trizio S, Bertolino A, Blasi G (2015) The role of the thalamus in schizophrenia from a neuroimaging perspective. Neurosci Biobehav Rev 54:57-75. CrossRef Medline

Pinto A, Jankowski M, Sesack SR (2003) Projections from the paraventricular nucleus of the thalamus to the rat prefrontal cortex and nucleus accumbens shell: ultrastructural characteristics and spatial relationships with dopamine afferents. J Comp Neurol 459:142-155. CrossRef Medline

Schobel SA, Lewandowski NM, Corcoran CM, Moore H, Brown T, Malaspina D, Small SA (2009) Differential targeting of the CA1 subfield of the hippocampal formation by schizophrenia and related psychotic disorders. Arch Gen Psychiatry 66:938-946. CrossRef Medline

Shah A, Lodge DJ (2013) A loss of hippocampal perineuronal nets produces deficits in dopamine system function: relevance to the positive symptoms of schizophrenia. Transl Psychiatry 3:e215. CrossRef Medline

Smith RE, Haroutunian V, Davis KL, Meador-Woodruff JH (2001) Vesicular glutamate transporter transcript expression in the thalamus in schizophrenia. Neuroreport 12:2885-2887. CrossRef Medline

Su HS, Bentivoglio M (1990) Thalamic midline cell populations projecting to the nucleus accumbens, amygdala, and hippocampus in the rat. J Comp Neurol 297:582-593. CrossRef Medline

Takamori S, Rhee JS, Rosenmund C, Jahn R (2000) Identification of a vesicular glutamate transporter that defines a glutamatergic phenotype in neurons. Nature 407:189-194. CrossRef Medline

Ungless MA, Grace AA (2012) Are you or aren't you? challenges associated with physiologically identifying dopamine neurons. Trends Neurosci 35: 422-430. CrossRef Medline

Zimmerman EC, Grace AA (2016) The nucleus reuniens of the midline thalamus gates prefrontal-hippocampal modulation of ventral tegmental area dopamine neuron activity. J Neurosci 36:8977-8984. CrossRef Medline 